\title{
Investigating Barriers and Challenges to Tuberculosis Service Delivery in Hard-to-Reach Riverine Areas: A Mixed-Methods Study in the Niger Delta Region of Nigeria
}

Chukwuka Alphonsus ( $\nabla$ alphchuk@yahoo.co.uk)

German Leprosy and TB Relief Association India https://orcid.org/0000-0001-6213-1426

Joseph N. Chukwu

German Leprosy and TB Relief Association

Tripti Pande

Research Institute of the McGill University Health Centre

Charles C. Nwafor

German Leprosy and TB Relief Association

Anthony 0. Meka

German Leprosy and TB Relief Association

Chinwe C. Eze

German Leprosy and TB Relief Association

Ngozi Ekeke

German Leprosy and TB Relief Association

Joy Ikebudu

German Leprosy and TB Relief Association

Moses C. Anyim

German Leprosy and TB Relief Association India

Jacob Creswell

Stop TB Partnership Geneva

Marina Smelyanskaya

Stop TB Partnership, Geneva

Kingsley N. Ukwaja

Federal Teaching Hospital, Abakaliki

Research article

Keywords: Tuberculosis, service delivery, diagnostic delays, Delay, hard-to-reach areas, Niger Delta

Posted Date: January 17th, 2020 
DOI: https://doi.org/10.21203/rs.2.21150/v1

License: (c) (1) This work is licensed under a Creative Commons Attribution 4.0 International License. Read Full License 


\section{Abstract}

Background Little is known about the challenges and barriers to tuberculosis (TB) service delivery in hardto-reach riverine populations in Nigeria. The missing TB cases in such key populations need to be found if the End TB targets are to be met. This study explored perceptions and attitudes related to TB, as well as the level of diagnostic and treatment delays in communities of the riverine Niger Delta.

Methods This was an exploratory mixed-methods study carried out in two states (Bayelsa and Delta) situated in the Niger Delta region in Nigeria. It consisted of quantitative surveys of community members and TB patients, FGDs with community members and KIls with health care workers.

Results The questionnaire survey was completed by 597 community members (51.6\% female) and 51 TB patients (56.9\% female); 73 community members and $15 \mathrm{HCWs}$ participated in FGDs and interviews respectively. Community members' mean [SD] knowledge and attitude scores were 6.1/10 [2.2] and $4.8 / 12$ [1.9] respectively. Older age $(>40 y)(p=0.04)$ and regular income $(p<0.001)$ were independent predictors of TB knowledge. Good TB knowledge (aOR 2.5; 95\% C.I. $1.5-4.4$ ) and formal education (aOR 5.8; 95\% C.I. 1.3 - 25.6) were associated with positive TB attitudes. Patients' TB knowledge was similar at 6.8/8 [1.5]. Most (98.8\%) respondents took $>1$ hour to access the nearest diagnostic centre. Mean patient-related and health system-related diagnostic delays were 16.3 and 3.7 weeks respectively. Mean treatment delay was found to be 0.5 weeks. Patient-related, financial, cultural and structural barriers were found to delay TB diagnosis and treatment in this environment. Belief in faith healing and herbal remedies, transport barriers, and negative HCW attitudes were prominent themes in FGDs. Problems transporting sputum samples and tracing mobile communities were primary HCW complaints.

Conclusions A number of barriers affect TB service delivery in hard-to-reach riverine communities in Nigeria. Our study suggests that an appropriately designed community intervention can improve TB service delivery in these communities. The main focus will be to address information asymmetry between service providers and the community, empower affected communities to find cases, engage informal providers such as patent medicine vendors, and strengthen the health system.

\section{Background}

Improving tuberculosis (TB) case detection has remained a global challenge. An estimated 10.4 million persons developed TB in 2017, however only 6.7 million new cases of TB were notified (1). India, Indonesia and Nigeria accounted for almost half (46\%) of the total gap between TB incidence and reported cases worldwide (1). Therefore, there is a need to improve TB case detection in these and other high burden countries. The World Health Organization (WHO) and Stop TB Partnership have called for a paradigm shift on how TB services are organised, moving from passive to active case finding particularly in key populations facing higher risk of TB (2-5). Furthermore, both agencies specify that TB testing and treatment services must reach at least $90 \%$ of these key populations by 2020 (5-7). Addressing barriers to TB service delivery among key populations is therefore critical to the overall goal of 
ending the TB epidemic (2-5). TB key populations vary by country and include people with increased exposure to TB due to where they live or work, people with limited access to services due to social, economic or legal barriers, and people with increased risk of TB because of biological or behavioural factors (2-5).

Nigeria is also among 14 countries with high burden of TB, TB/HIV and multidrug-resistant TB (MDR-TB) [1]. In 2017, only about $24 \%$ of the estimated incident cases of TB in the country were notified [1]. To address this, a number of systematic TB screening strategies have been carried out in Nigeria targeting the general population, TB contacts, persons living with HIV (PLHIV), children, urban and mobile populations (6-10). In Nigeria's riverine areas, limited land mass leads to uneven distribution of health facilities in the area and residents require costly marine transport - where a return trip may cost up to US\$30 to access appropriate health services (11). As such, people living in riverine areas have limited access to quality TB services and many are highly mobile (fisher folk and traders) further complicating TB diagnosis. The most common occupation in riverine areas is fishing and these rural areas are served by itinerant traders who trade with the fisher folks (12).

In 2015, Nigeria's case notification rate (CNR) was 54 per 100000 population. In the riverine populations of the Niger Delta, the CNR was 9 per 100 000. Previous studies in Brazil and Nigeria have also shown very low TB case detection rates in riverine compared to inland areas $(13,14)$. A study conducted in 2016 has shown poor knowledge of TB among women living in the Atlantic coastline of Nigeria (15). Studies conducted in rural and coastal regions of Nigeria have found that financial constraints, distance and poor knowledge are major barriers to accessing TB services (16-18). Lack of accessibility to services, and poor knowledge of TB may contribute to the high rate of Nigeria's missing TB cases. Furthermore, low case detection rates, high mortality rates and stigma may also be contributing factors. Previous studies in Nigeria have illustrated challenges faced by TB patients, however little is known about TB in the communities of the Niger delta. There is also a lack of accurate data of the TB burden in these populations.

In 2017, GLRA received a TB REACH Wave 5 grant to implement a community-driven, output-based approach to intensified TB case finding in 6 Local Government Areas (LGAs) in the Niger Delta. The project sought to use existing community structures to raise awareness about TB and improve access to TB diagnostic, treatment and preventive services. The first part of the project was to gain a baseline understanding of the barriers to accessing TB diagnosis and care hence this study.

The aim of the study was to explore the understanding, perceptions and attitudes related to TB, as well as assess level of diagnostic and treatment delays in communities of the riverine Niger Delta. Understanding the barriers to TB service delivery in the intervention communities was important in designing interventions to increase case detection rates as well as generate local evidence for further policy making by the National TB Control Programme in Nigeria.

Study population and sampling 
To achieve $50 \%$ prevalence of good knowledge, $95 \%$ confidence level and a precision of $5 \%$, we estimated a minimum sample size of 384 for the community member survey. To ensure higher precision, we interviewed 600 community members (100 per LGA). This number was based on feasibility of data collection. As all LGAs have approximately the same population, equal number of community members were sought from each LGA.

The semi-structured questionnaire interviews were carried-out among community members and TB patients who were receiving treatment in the study area. The community survey utilised simple random sampling to select households based on the census enumeration area for each LGA. In each selected household, the head of the household (or next eligible person) was recruited until the desired sample size was reached. Community members who participated in this survey were different from those who participated in the FGD.

To avoid intervention bias, only patients who were receiving/have received treatment in all the TB treatment centres in the study area within 6 months prior to the implementation of the project (i.e. December 2016) were selected for the patient survey.

For the community health care worker (HCW) interviews, three engaged HCWs were purposively sampled from each LGA (total 18 interviews). This was chosen based on feasibility of data collection and also to ensure data saturation.

\section{Instruments and data collection}

The community survey was carried-out using pre-tested semi-structured interviewer-administered questionnaires adapted from USAID/TBCARE II (19). A scoring system was applied to assess the level of knowledge of each respondent: one point was awarded for each correct answer; no points were given for an incorrect answer (20). In addition, participants were asked to respond to questions related to their beliefs about and/or attitudes towards TB. A scoring system was also applied, with one point given for each positive answer and no points given for a negative answer (20).

The FGD and KII guides probed on how TB control services can be improved and the type of support needed in the community. For the qualitative study, FGDs were based on the Explanatory Model Interview Catalogue (EMIC) framework for cultural epidemiology (21). This framework was chosen to ensure internal/face validation of the FGD guide. The study instruments were reviewed by a group of academics, epidemiologists and public health physicians, social scientists and TB control specialists involved in the State Tuberculosis, Leprosy and Buruli ulcer Control Programmes of Delta and Bayelsa States who considered them to have face validity. The reviews led to the removal of sections of the original tool not related to this study (19). The instruments were developed in English, but interviews were conducted in Pidgin spoken by respondents in the study areas. The questionnaire was pretested among 20 adults in a rural community and 10 health care workers outside the study area and subsequently modified. 
In total, 9 FGDs were held (five with males and four with females), consisting of 73 community members engaged in farming and fishing. Five of the FGDs were held among younger adults (18-40 years) and four were held among older adults ( $>40$ years). In addition, 15 key informant interviews (KIls) were conducted with Local Government TB \& Leprosy supervisors - who coordinate TB control in their respective local government areas and the next most experienced TB health worker. The interviews drew on health workers' experiences with, and attitudes of TB patients who were diagnosed and treated in their Local Government Areas (LGAs).

\section{Data analysis}

The questionnaire data were checked and double-entered, cleaned and analysed using Epi Info 3.4.1 (CDC, Atlanta, GA USA). A knowledge score for TB was calculated for each participant. Respondents with a knowledge or attitude score of $>50 \%$ were considered to have good knowledge or attitude, while those with $\leq 50 \%$ were considered to have poor knowledge or attitude to TB. Continuous variables were summarized as means $\pm S D$, and categorical variables as proportions. Categorical variables were compared using the Chi Square $\left(\chi^{2}\right)$ test for proportions. Multivariable logistic regression analyses were performed to determine factors associated with good knowledge or attitude to TB. A p-value $<0.05$ was considered significant. The FGDs and KIls were transcribed in English immediately after the interview and entered into a Microsoft word processing package. Four reviewers analysed the transcripts using thematic analysis. Analysis of transcripts proceeded based on coding and a framework for analysis; the meaning units were then built up into themes and subthemes and used to develop textual descriptions of the experiences. Disagreements in coding interpretation were reviewed and decided by consensus. For each key analytic theme, data extracts were identified on the basis of being representative or interesting illustrations of an emerging issue.

\section{Ethics Statement}

The study was approved by the health research ethics committee of the Delta State Ministry of Health, Asaba, Delta State Nigeria with reference number HC/218/VOL IV/134. Also, permission was obtained from the State TB, Leprosy and Buruli Ulcer Control Programme of Delta and Bayelsa State. A signed informed consent was obtained from all study participants. Participants were informed that their participation in the survey/interviews/FGD would not have any bearing on their medical care/access

\section{Results}

The response rates for community, patients and HCWs were 99\% (597/600), 100\% (51/51) and 83\% (15/18), respectively. Community members and HCWs who did not participate were unable to do so due to timing constraints. Table 1 represents sociodemographic characteristics of all study participants. In the narrative below, community perspectives are presented followed by patient and HCWs perspectives.

\section{Characteristics of the respondents}


As shown in Table 1, within the community, more males 335 (56.1\%) than females 262 (43.9\%) were surveyed. Among TB patients this dynamic was reversed with slightly more females 29 (56.9\%) than males $22(43.1 \%)$ interviewed. Of the community members interviewed, $361(60.5 \%)$ were aged $\leq 40$ years while $51,37(72.5 \%)$ of the TB patients surveyed were aged $\leq 40$ years. Secondary education was the highest education level achieved by 304 (50.4\%) of community members and 33 (64.7\%) of TB patients. Most community members and TB patients lived in rural settings and were from the ljaw ethnic group. Farming was the most common occupation among community members $(253,42.4 \%)$, and $26(51.0 \%)$ of TB patients were unemployed. For the TB patients, 50 (98.0\%) had pulmonary TB and all were bacteriologically confirmed. Only TB patients were tested for HIV with 49 (96.1\%) reporting as being HIV negative.

Nine FGD sessions comprising 73 adults (40 male; and 33 female) and KIls were held with 15 health workers. All the participants for the FGD resided in the study area, and KIls were held with health workers involved in providing TB services in the study communities.

\section{Community perspective: facts and fiction}

Knowledge of, and attitude towards TB: Table 2 illustrates the aggregate knowledge and attitude questionnaire scores by community members. The overall mean [SD] knowledge score was 6.1 [2.2] (maximum 10). A total of 391 (65.5\%; $61.5-69.3 \%$ ) of the respondents had good knowledge of TB. Older (>40 years old) respondents had a higher overall knowledge of TB compared to younger ( $\leq 40$ years old) participants $(71.2 \%$ vs. $61.8 \%$; $p=0.018)$.

However, during the FGDs with both younger and older community members, it was mentioned that TB is transferrable through sharing utensils, eating with a person with $T B$, and is caused by excessive drinking and/or smoking as well as contaminated foods or water.

"[TB] is a transferable disease caused by cough, you can get it by sharing utensils".

Male FGD participant (18-29 age group), Brass

In two FGDs, participants mentioned witchcraft and spiritual attacks as a cause of TB. Patients in all nine FGDs identified cough as a cause for TB and weight loss was mentioned by participants of eight FGDs.

The mean (SD) attitude score was $4.8 \pm 1.9$ (maximum 12) suggesting that generally they had a poor attitude towards TB. A total of $492(82.4 \% ; 79.15-85.26)$ had poor attitude towards TB. Only 105 $(17.6 \% ; 14.7-20.9 \%)$ of the community members had appropriate attitude towards TB. When asked about attitudes and beliefs, community members believed that the onset of TB would result into job loss, but most did not think that women with TB will be infertile.

Access to TB services and health-seeking behaviour for tuberculosis: Community members' access to TB diagnostic services and their perceived health-seeking behaviour for TB symptoms are shown in Table 3 . Only 161 (27.0\%) of the community members had received some information about TB in the six months 
preceding the survey by healthcare providers 75 (46.6\%), mass media $43(26.7 \%)$, family/friends 20 (12.4\%) and religious places 12 (7.5\%). Overall, 589 (98.7\%) of the community members reported that it would take them an hour or more to get to the nearest health facility that diagnoses and treats TB in their community. Also, 356 (59.6\%) of the community members reported having to pay for transportation to get to the health facility. Furthermore, $163(27.3 \%)$ and $273(45.7 \%)$ of the community members reported that they have to pay out-of-pocket to access a healthcare provider and laboratory services respectively in the health facility. Self-treatment $(181,30.3 \%)$, medicine vendors $(86,14.4 \%)$ and public clinic/hospital $(120,20.1 \%)$ were the most popular ways/sites of first visit for cough among surveyed community members.

FGD participants from South ljaw and Ekeremor indicated that local chemists were their first point of care for TB. In these groups, visiting traditional healers and pastors or churches for treatment were also mentioned.

"Some people might go to meet their pastors to pray for them before going to the clinic. Believing that God is the solution to all problems, that is why they go to meet their pastors."

Female FGD participant (aged 40 and over), Ekeremor

Perceptions around TB and gender: Across all communities, 348 (58.3\%) of survey participants also thought men were more likely to get TB than women. When asked about attitudes and beliefs, community members believed that the onset of TB would result in job loss, but most did not think that women with TB will be infertile as is common in some other communities (22). Furthermore, 395 (66.2\%) community members thought that women would need to ask permission from their husbands and/or relatives to access healthcare.

Delays in accessing TB services: The community members' perceived mean ( $\pm S D)$ patient delay was 2.2( \pm 2.9$)$ weeks (median; inter quartile range $1 ; 1-2$ weeks). Also, the community members believed that presumptive TB patients in their community will require a mean (SD) $2.1( \pm 1.2)$ health facility visits (median, IQR; 2, 1-3) to get a diagnosis of TB in their community. Also, their perceived mean (SD) delay from contact with the health system to receiving a diagnosis of TB was $5.7( \pm 7.3)$ days (median, IQR; 3,1 -7 days), and the perceived mean (SD) treatment delay was 6.7( \pm 13.7$)$ days (median, IQR; $3,1-7$ days).

Concerns about costs associated with TB treatment and care and lack of knowledge/understanding of the fact that TB treatment and care were provided for free were among the top causes of treatment delay according to most FGDs. In Patani, FGDs with both males aged over 40 and females aged 18-39 also indicated that shame could be a reason why some people with TB do not seek care.

"Some actually know the treatment is free, but they are still ashamed to go for treatment"

Female FGD participant (aged 18 to 39), Patani 
In Southern ljaw and Ekeremor, where traditional healers were mentioned, the FGD participants stated that getting native drugs and relying on native treatment first was the cause of delay for many.

In all, FGD themes such as the need for more awareness around TB in the community, bringing health centres and health workers closer to the communities with the most need to alleviate travel costs for patients, and the need to support people with TB in the community with travel allowances and treatment adherence services came through.

Factors impacting knowledge and attitude towards TB: Logistic regression analysis was used to understand factors associated with knowledge and attitude towards TB. Educational status $(p=0.028)$, residence $(p=0.006)$, ethnicity $(p=0.045)$, occupation $(p=0.008)$ and monthly household income status $(p=0.004)$ were associated with good knowledge of TB. In multivariable logistic regression analyses (see Table 4), only older age (adjusted odds ratio (aOR) 1.5, 95\% Cl 1.1-2.3), rural residence (aOR $2.4,95 \% \mathrm{Cl}$ 1.7-4.0), Itsekiri ethnic group (aOR 3.0, 95\% $\mathrm{Cl} 1.1-8.8$ ), and having a regular household income (aOR $2.4,95 \% \mathrm{Cl} 1.4-3.9)$ were independent predictors of good knowledge of TB. Additionally, good knowledge of TB among the community members was associated with good attitude $(p=0.001)$. Furthermore, formal education (aOR 5.8, 95\% C.I.1.3-25.6), Itsekiri ethnicity (aOR 6.1, 95\% C.I. 1.6-23.6), and good knowledge (aOR 2.5, 95\% C.I. 1.5-4.4) were independent predictors of positive attitudes for TB.

\section{Patient Perspectives and Experiences}

Knowledge of TB: The TB patients surveyed generally had a good knowledge of TB (Table S4). The overall mean (SD) knowledge score was $6.8 \pm 1.5$ (maximum 8). Table 5 shows that that $13(25.5 \%)$ patients didn't know that TB is caused by an infectious agent/germ and $12(23.5 \%)$ didn't know that TB can be transmitted through inhalation of air droplet from affected persons. Overall, 45 (88.2\%; 76.1 $95.6 \%)$ of the patients had good knowledge of TB.

Perceptions of TB and access to TB care: Table 6 presents TB patient's perceptions of TB, where 29 $(56.8 \%)$ of patients indicated that they felt scared when they found out they had TB; $40(78.4 \%)$ said that they informed their family and friends that they had TB, and $30(58.8 \%)$ patients did not feel discriminated against by the community. When asked about acquiring diagnosis, all patients reported having to travel longer than 1 hour to reach the health facility (Table 3 ) for diagnosis and treatment of TB; $37(72.5 \%)$ had to pay for transportation to reach the facility and $33(64.7 \%)$ found that the health facility had convenient hours of service. A total of $35(68.6 \%)$ of the patients had received some information about TB in the six months prior to their diagnosis; and healthcare providers 23 (45.1\%), and family/friends 14 (27.5\%) were the major sources of information on TB. 
Table 7 shows patients' health seeking behavior for TB. Fifty (98.0\%) of patients reported taking a previous treatment prior to being diagnosed with TB, and 43 (84.4\%) reported that their symptoms either worsened or remained the same. Patients had repeated visits with the same provider $(22,43.1 \%)$ as well as different providers within the same facility $(16,31.3 \%)$. When asked reasons for delaying seeking care, $35(68.6 \%)$ of patients reported that they were not aware of the severity of the symptoms.

Diagnostic and treatment delay: The TB patients' mean [SD] delay from the onset of TB symptoms to visit to any health facility was 16.3 [18.7] weeks (median; inter quartile range 12; 4 - 24 weeks) with 32 $(62.7 \%)$ of patients seeking care after four weeks of symptom onset. Also, the delay from the patient's first visit to any health facility until they were informed they had TB was a mean [SD] 3.7 [6.9] weeks (median, IQR; 1, $1-4$ weeks). Thus, the overall mean [SD] diagnosis delay of the TB patients was 20.0 [21.7] weeks (median; inter quartile range 13; 5 - 25 weeks).

Thirty-eight (74.5\%) of patients started treatment within three days of TB diagnosis. The mean [SD] treatment delay following a TB diagnosis was 3.5 [5.1] days (median, IQR; 1, 1 -4 days). Mean diagnosis delay did not differ among patients with good vs poor knowledge of TB (19.3 [18.9] vs 25.5 [35.2] weeks; $\mathrm{p}=0.515)$. Furthermore, the mean diagnostic delay did not differ according to the patients' demographic characteristics ( $p>0.05$ ), access to care (Table S5; $p>0.05$ ), and their health-seeking behavior (Table 7; $p>0.05)$.

\section{Health workers Perspectives}

Causes of patient delay and assessment of resources: Fifteen KIls with HCWs were conducted. The major themes emerging from these KII's regarding provider attitudes were: availability of materials for testing, provider trainings, challenges to testing, increasing knowledge of TB and motivating HCWs towards TB. HCWs mentioned that materials and drugs were not a problem for their facilities. All facilities had drugs provided by the state and materials were immediately available to conduct TB diagnostic testing and treatment. However, HCWs did mention some challenges to testing, specifically sputum transportation and communication of results post testing. HCWs focused largely on motivating HCWs towards TB. Some HCWs indicated that training personnel through institutions or Non-Governmental Organizations (NGOs) would be a good way to increase awareness of TB. Others indicated that incentives and providing salaries would help increase HCW motivation towards TB testing.

"If something (money) can be given to the DOTS workers, maybe quarterly, just to encourage them to be active, especially now that the Government does not pay salaries"

[KII TBLS Patani]. 
When asked regarding patient delay, HCWs noted that patients only come to them when they are in critical condition.

"They first go to spiritual homes and when they have tried all that without success, then they come to us" (KII Asst. TBLS Southern ljaw).

"Since they think it's a spiritual attack, some go to churches. Some use leaves, roots and herbs. They only come to the hospital when the sickness gets worse" (KII Brass DOTS FP).

These themes were similar to those presented by the community as well as the TB patients above.

\section{Discussion}

This study reveals the contextual circumstances influencing the demand and supply of TB services in the riverine areas of Nigeria. It also suggests mechanisms that may inform their improvement.

In this study, we have shown that community members and TB patients in the Niger Delta region of Nigeria have above average knowledge of TB. Our results also demonstrate gaps in knowledge around aetiology of TB, mode of transmission of TB as well as where care is best sought to address the disease. These gaps may have led to negative community attitudes, and perceptions about TB as well as treatment delays. Some community members indicated that TB was due to witchcraft and sharing of utensils. Similar findings have been shown in studies conducted in Nepal, India and Lagos, Nigeria (2325). These observations are also consistent with observations in other hard-to-reach rural populations where awareness of TB may be high but population level knowledge of the aetiology and mode of transmission of the disease is low [26-27]. In addition, we found that older age, residence, ethnicity and having a regular monthly household income predicted good knowledge of $T B$, and having a formal education and good knowledge predicted appropriate attitude towards TB. Improved TB case detection in hard-to-reach riverine populations of Nigeria can be achieved through undertaking appropriate health education programmes especially targeting the young, the poor and those living in rural areas.

This study also reveals inappropriate community attitudes, and poor patient perceptions about TB in hard-to-reach riverine areas. Most of the deficits in the community members' attitude to TB centred on the most at-risk groups and gender differences in TB. In addition, we found that one-fifth of TB patients surveyed had not disclosed their illness status to their family members/friends, and $72.5 \%$ were afraid or depressed upon learning of their TB diagnosis. This poor attitude to, and poor perceptions of TB may be because of their lack of knowledge about the disease and the improper understanding that TB has 
supernatural causes e.g., witchcraft. It is reassuring that good knowledge of the disease predicted better community attitude to TB.

Our study also shows that there is poor community access to TB services and poor health seeking by community members and TB patients in riverine areas.. Almost all the participants perceived that it will take a trip of over one hour to get to a TB diagnostic and treatment facility nearest to their community. All the TB patients surveyed also experienced this. In agreement with community members and patients, HCWs also identified accessibility as a major issue affecting delay in diagnosis of TB. Furthermore, HCWs noted that due to inaccessibility of health clinics, patients would visit them as a 'last resort'. Such challenges are common for other high-burden settings, where patients experience tremendous challenges to care, incurring catastrophic costs along the way (28). To address these barriers, implementers could look into conducting outreach interventions using motorboats. Use of incentives for individuals with presumptive TB, to compensate for travel costs, may assist in reducing the distance to health facilities and thus increase TB service uptake.

HCWs in facilities without TB diagnostic capacity experienced many challenges with sputum transportation, as well as tracing registered TB patients who were lost to follow-up. HCWs also noted that lack of incentives and salaries for staff may be affecting the number of staff working in TB. National programs may benefit from providing incentives to HCW to attract/retain staff working in TB thus increasing patient interactions and education/counselling of TB diagnosis/treatment.

In addition, this study showed that patient related delay was the greatest contributor to total delay. This is consistent with findings from a study in Nigeria, where patient related delay was the greatest contributor to total delay in TB diagnosis (29). Moreover, because TB services are not readily available in their communities and expensive marine transport is needed to get to where they are located, TB patients in riverine areas of Nigeria experience very long delays in TB diagnosis and treatment compared with the delays observed in other hard to reach populations in the country $[17,20]$. Even when the community members / patients decided to seek care, they tended to favour informal health providers such as PMVs who are readily available and who charged lower fees. This finding emphasizes the need for increased education and trainings for community members on causes of TB, as well as the need to engage with PMVs and/or local chemists when planning TB case finding activities to bring services closer to hard-to reach populations.

A key strength of this study was that it was carried out in hard-to-reach riverine communities in the Niger Delta where very few TB case detection strategies are implemented and where little research has been previously conducted. In addition, data source triangulation strengthened the validity of our quantitative findings because it ensured wider representation of community experiences and views on TB in riverine areas thereby increasing its potential for relevance in other low-resource settings in Sub-Saharan Africa. Therefore, the findings of this study may serve as a guide to programme managers and health policymakers in designing culturally-sensitive community education and active TB case-finding interventions in riverine areas. 
This study has a few limitations. Firstly, causal inferences were not possible based on the findings of our quantitative analysis. Second, the small sample size of the TB patients suggests that the findings of the bivariate analysis should be interpreted with caution. Third, there was possibility of interviewer and response bias where the research assistant or participant consciously or subconsciously gave cues or answers influenced by the other. Finally, there were no FGDs or KIIs with TB patients which is a potential limitation of the study, however, because of high discovered TB prevalence in the communities, community members could act as proxies for people with TB for the FGDs.

\section{Conclusions}

There are knowledge, access, cultural, structural and economic barriers that affect TB case detection and management in hard-to-reach riverine communities in Nigeria. Our study suggests that an appropriately designed community intervention can improve TB service delivery in these communities. The main focus will be to address information asymmetry between service providers and the community, empower affected communities to find cases, engage informal providers such as PMVs, and strengthen the health system. Also, there is a need for the National TB Programme in Nigeria to develop culturally-sensitive community TB education programmes in this setting which should address local misconceptions and interpretation of TB, early care-seeking, and should emphasise that the disease is curable in order to reduce fears encountered by affected persons.

\section{Abbreviations}

aOR - adjusted odds ratio

CNR - Case Notification Rate

EMIC - Explanatory Model Interview Catalogue

FGD - Focus Group Discussion

HCW - Healthcare Worker

KII - Key Informant Interview

LGAs - Local Government Areas

MDR-TB - Multidrug-resistant TB

NGOs - Non-Governmental Organizations

PLHIV - Persons living with HIV

SD - Standard Deviation 
TB - Tuberculosis

TBLS - TB Leprosy Supervisor

WHO - World Health Organization

\section{Declarations}

Ethical approval and consent to participate

The study was approved by the health research ethics committee of the Delta State Ministry of Health, Asaba, Delta State Nigeria with reference number HC/218/VOL IV/134. Also, permission was obtained from the State TB, Leprosy and Buruli Ulcer Control Programme of Delta and Bayelsa State. A signed informed consent was obtained from all study participants. Participants were informed that their participation in the survey / interviews / FGD would not have any bearing on their medical care / access

Consent for publication

Not applicable

Competing interests

The authors declare that they have no competing interests

Statement of funding

This work was supported by the Stop TB Partnership's TB REACH initiative (Grant number STBP/TBREACH/GSA/W5-04) and was funded by the Government of Canada. The funder had no role in the primary data collection, data analysis, data interpretation, or writing of the report. The corresponding author had full access to all the data in the study and had final responsibility for the decision to submit for publication.

Authors' contributions:

CA, JNC, CCN and CCE conceived the study; CA, JNC, CCN, AOM, NE and CCE designed the study protocol; all authors collected data, performed data entry and carried out the data analysis and interpretation; KNU, CA, JNC, TP, and MS, drafted the manuscript; All authors critically revised the manuscript for intellectual content. All authors read and approved the final manuscript.

\section{Acknowledgements}

We thank the State TB, Leprosy and Buruli ulcer Control Programme of Delta and Bayelsa States for their support. 
The dataset are available from German Leprosy \& TB Relief Association (dahw.nigeria@dahw.org) upon reasonable request

\section{References}

1. World Health Organization. WHO Global Tuberculosis Report 20172018 [Available from: https://www.who.int/tb/publications/global_report/gtbr2017_main_text.pdf?u\%20a=1.

2. World Health Organization. The End TB Strategy: Global Strategy and Targets for Tuberculosis, Prevention, Care and Control after 20152015 [Available from: https://www.who.int/tb/strategy/End_TB_Strategy.pdf.

3. World Health Organization. Systematic screening for active tuberculosis: principles and recommendations: World Health Organization; 2013.

4. Stop TB Partnership. Partnership. The Global Plan to End TB: The Paradigm Shift 2016-2020. 2015. 2016.

5. Stop TB Partnership. Improving tuberculosis case detection: a compendium of TB REACH case studies, lessons learned and a monitoring and evaluation framework 2019 [Available from: http://www.stoptb.org/../TB_Case_Studies.pdf.

6. Ogbudebe CL, Chukwu JN, Nwafor CC, Meka AO, Ekeke N, Madichie NO, et al. Reaching the underserved: Active tuberculosis case finding in urban slums in southeastern Nigeria. International journal of mycobacteriology. 2015;4(1):18-24.

7. Oshi DC, Chukwu JN, Nwafor CC, Meka AO, Madichie NO, Ogbudebe CL, et al. Does intensified case finding increase tuberculosis case notification among children in resource-poor settings? A report from Nigeria. International journal of mycobacteriology. 2016;5(1):44-50.

8. Adejumo A, Azuogu B, Okorie O, Lawal O, Onazi O, Gidado M, et al. Community referral for presumptive TB in Nigeria: a comparison of four models of active case finding. BMC Public Health. 2016;16(1):177.

9. John S, Gidado M, Dahiru T, Fanning A, Codlin A, Creswell J. Tuberculosis among nomads in Adamawa, Nigeria: outcomes from two years of active case finding. The International Journal of Tuberculosis and Lung Disease. 2015;19(4):463-8.

10. Oshi DC, Omeje JC, Oshi SN, Alobu IN, Chukwu NE, Nwokocha C, et al. An evaluation of innovative community-based approaches and systematic tuberculosis screening to improve tuberculosis case detection in Ebonyi state, Nigeria. International journal of mycobacteriology. 2017;6(3):246.

11. Ogbonna C. NYSC members in Bayelsa want improved water transportation in riverine areas: Sundiatapost; 2017 [Available from: https://sundiatapost.com/2017/03/05/nysc-members-inbayelsa-want-improved-water-transportation-in-riverine-areas/.

12. Eze F, Oti P, Odigbo B. Socio-Economic Implications of Essential Commodities' Price Differentials in Riverine and Hinterland Areas of Nigeria. Res J Fin Account. 2016;7(18):23-7. 
13. Garrido MdS, Bührer-Sékula S, Souza ABd, Ramasawmy R, Quincó PdL, Monte RL, et al. Temporal distribution of tuberculosis in the State of Amazonas, Brazil. Revista da Sociedade Brasileira de Medicina Tropical. 2015;48:63-9.

14. Nwidu L, Blessing O, Abanee P. The prevalence of tuberculosis and leprosy in primary health care levels in rivers state, Nigeria. Biomed Pharmcol J. 2008;2:265-74.

15. Afolabi B, Ezedinachi E, Okon B, Arikpo I. Raising awareness about tuberculosis among women living in rural communities on the Atlantic coastline of Nigeria. Transl Biomed. 2016;7(3).

16. Ukwaja KN, Alobu I, Hopewell PC. The high cost of free tuberculosis services: patient and household costs associated with tuberculosis care in Ebonyi State, Nigeria. PloS one. 2013;8(8):e73134.

17. Ukwaja KN, Alobu I, Nweke CO, Onyenwe EC. Healthcare-seeking behavior, treatment delays and its determinants among pulmonary tuberculosis patients in rural Nigeria: a cross-sectional study. BMC health services research. 2013;13(1):25.

18. Uchenna OU, Ngozi CJ. Assessment of tuberculosis-related knowledge, attitudes and practices in Enugu, South East Nigeria. Journal of infectious Diseases and Immunity. 2014;6(1):1-9.

19. USAID TB CARE II. Reducing delays in TB diagnosis: data collection tools 2018 [Available from: https://www.challengetb.org/publications/tools/ua/Data_Collection_Tool_TB_Patient_Delay.pdf

20. Uchenna OU, Chukwu J, Onyeonoro U, Oshi D, Nwafor C, Meka A, et al. Pattern and magnitude of treatment delay among TB patients in five states in southern Nigeria. Annals of Tropical Medicine and Public Health. 2012;5(3):173.

21. Weiss M. Explanatory Model Interview Catalogue (EMIC): Framework for comparative study of illness. Transcultural psychiatry. 1997;34(2):235-63.

22. Khan JA, Irfan M, Zaki A, Beg M, Hussain SF, Rizvi N. Knowledge, attitude and misconceptions regarding tuberculosis in Pakistani patients. Journal of Pakistan Medical Association. 2006;56(5):211.

23. Chinnakali P, Ramakrishnan J, Vasudevan K, Gurumurthy J, Upadhyay RP, Panigrahi KC. Level of awareness about tuberculosis in urban slums: Implications for advocacy and communication strategy planning in the National program. Lung India: official organ of Indian Chest Society. 2013;30(2):139.

24. Amgain K, Maharjan M, Paudel DP, Dhital M, Amgain G, Paneru DP. Awareness and attitude of pulmonary tuberculosis patients toward tuberculosis: A cross-sectional study from Chitwan district of Nepal. International Journal of Health \& Allied Sciences. 2014;3(4):216.

25. Uchenna OU, Ngozi CJJJoiD, Immunity. Assessment of tuberculosis-related knowledge, attitudes and practices in Enugu, South East Nigeria. 2014;6(1):1-9.

26. Zhang T, Liu X, Bromley H, Tang S. Perceptions of tuberculosis and health seeking behaviour in rural Inner Mongolia, China. Health Policy 2007;81(2-3):155-65.

27. Tobin EA, Okojie PW, Isah EC. Community knowledge and attitude to pulmonary tuberculosis in rural Edo state, Nigeria. Ann Afr Med 2013;12:148-54 
28. Ukwaja KN, Alobu I, Abimbola S, Hopewell PC. Household catastrophic payments for tuberculosis care in Nigeria: incidence, determinants, and policy implications for universal health coverage. Infectious diseases of poverty. 2013;2(1):21.

29. Odusanya OO, Babafemi JO. Patterns of delays amongst pulmonary tuberculosis patients in Lagos, Nigeria. BMC public health. 2004;4(1):18.

\section{Tables}

Table 1: Socio-demographic characteristics of community members $(N=597)$ and $T B$ patients $(N=51)$ 


\begin{tabular}{|c|c|c|}
\hline Variables & $\begin{array}{l}\text { Community members } \\
\mathrm{n}(\%)\end{array}$ & $\begin{array}{l}\text { TB patients } \\
\mathrm{n}(\%)\end{array}$ \\
\hline \multicolumn{3}{|l|}{ Age group (years) } \\
\hline$\leq 40$ & $361(60.5)$ & $37(72.5)$ \\
\hline$>40$ & $236(39.5)$ & $14(27.5)$ \\
\hline \multicolumn{3}{|l|}{ Gender } \\
\hline Female & $262(43.9)$ & $29(56.9)$ \\
\hline Male & $335(56.1)$ & $22(43.1)$ \\
\hline \multicolumn{3}{|l|}{ Educational status } \\
\hline No formal education & $44(7.4)$ & $3(5.9)$ \\
\hline Primary & $137(22.9)$ & $13(25.5)$ \\
\hline Secondary & $304(50.9)$ & $33(64.7)$ \\
\hline Tertiary & $112(18.8)$ & $2(3.9)$ \\
\hline \multicolumn{3}{|l|}{ Marital status } \\
\hline Single & $152(25.5)$ & $18(35.3)$ \\
\hline Married & $400(67.0)$ & $26(51.0)$ \\
\hline Separated/Divorced & $27(4.5)$ & 7 (13.7) \\
\hline Widowed & $18(3.0)$ & \\
\hline \multicolumn{3}{|l|}{ Residence } \\
\hline Rural & 493 (82.6) & $50(98.0)$ \\
\hline Urban & $104(17.4)$ & $1(2.0)$ \\
\hline \multicolumn{3}{|l|}{ Ethnic group } \\
\hline Igbo & $27(4.5)$ & $1(2.0)$ \\
\hline Ijaw & 463 (77.6) & $41(80.4)$ \\
\hline Itsekiri & $45(7.5)$ & 7 (13.7) \\
\hline Other & $62(10.4)$ & $2(3.9)$ \\
\hline \multicolumn{3}{|l|}{ Occupation } \\
\hline Public servant & $111(18.6)$ & $2(3.9)$ \\
\hline Professional & $48(8.0)$ & - \\
\hline House wife & $27(4.5)$ & $1(2.0)$ \\
\hline Private sector & $32(5.4)$ & $4(7.8)$ \\
\hline Farmer & $253(42.4)$ & $18(35.3)$ \\
\hline Unemployed & $126(21.1)$ & $26(51.0)$ \\
\hline \multicolumn{3}{|l|}{ Monthly household income } \\
\hline Irregular income & $244(40.9)$ & $10(19.6)$ \\
\hline No defined income & $212(35.5)$ & $30(58.8)$ \\
\hline Regular income & $141(23.6)$ & $11(21.6)$ \\
\hline \multicolumn{3}{|l|}{ Site of TB disease } \\
\hline Pulmonary & & $50(98.0)$ \\
\hline Extrapulmonary & & $1(2.0)$ \\
\hline \multicolumn{3}{|l|}{ Type of TB diagnosis } \\
\hline Bacteriological & & $50(98.0)$ \\
\hline Clinical & & $1(2.0)$ \\
\hline \multicolumn{3}{|c|}{ Human immunodeficiency virus status } \\
\hline Negative & & $49(96.1)$ \\
\hline Positive & & $2(3.9)$ \\
\hline
\end{tabular}

Table 2: Distribution of community' knowledge of, and attitude to tuberculosis according to their age-group (N = 597) 


\begin{tabular}{|c|c|c|c|c|}
\hline Variable & n (\%; 95\% C I) & $\begin{array}{l}\leq 40 \text { years } \\
\text { n }(\% ; 95 \% \text { C. I. })\end{array}$ & $\begin{array}{l}>40 \text { years } \\
\text { n }(\% ; 95 \% \text { C. I.) }\end{array}$ & P-value \\
\hline Total & 597 & 361 & 236 & \\
\hline \% knowledge score & & & & 0.008 \\
\hline$\leq 30$ & $76(12.7 ; 10.2-15.7)$ & $44(12.2 ; 9.1-16.1)$ & 32 (13.6; 9.5 - 18.6) & \\
\hline $31-50$ & $130(21.8 ; 18.6-25.3)$ & $94(26.0 ; 21.7-30.9)$ & $36(15.3 ; 10.9-20.5)$ & \\
\hline $51-70$ & $223(37.4 ; 33.5-41.4)$ & $134(37.1 ; 32.2-42.4)$ & 89 (37.7; $31.5-44.2)$ & \\
\hline$>70$ & $168(28.1 ; 24.6-32.0)$ & $89(24.7 ; 20.4-29.5)$ & 79 (33.5; 27.5 - 39.9) & \\
\hline Good knowledge (>50\%) & $391(65.5 ; 61.5-69.3)$ & $223(61.8 ; 56.5-66.8)$ & $168(71.2 ; 65.0-76.9)$ & 0.018 \\
\hline Poor Knowledge $(\leq 50 \%)$ & $206(34.5 ; 30.7-38.5)$ & $138(38.2 ; 33.2-43.5)$ & $68(28.8 ; 23.1-35.0)$ & \\
\hline$\%$ attitude score & & & & 0.074 \\
\hline$\leq 30$ & $154(25.8 ; 22.4-29.5)$ & $80(22.2 ; 18.1-26.9)$ & $74(31.4 ; 25.5-37.7)$ & \\
\hline $31-50$ & $338(56.6 ; 52.5-60.6)$ & $217(60.1 ; 54.8-65.2)$ & $121(51.3 ; 44.7-57.8)$ & \\
\hline $51-70$ & $87(14.6 ; 11.9-17.7)$ & $54(15.0 ; 11.5-19.2)$ & $33(14.0 ; 9.8-19.1)$ & \\
\hline$>70$ & $18(3.0 ; 1.9-4.8)$ & $10(2.8 ; 1.4-5.2)$ & $8(3.4 ; 1.5-6.6)$ & \\
\hline Appropriate attitude (>50\%) & $105(17.6 ; 14.7-20.9)$ & $64(17.7 ; 14.0-22.2)$ & $41(17.4 ; 12.8-22.8)$ & 0.911 \\
\hline Poor attitude $(\leq 50 \%)$ & $492(82.4 ; 79.15-85.26)$ & $297(82.3 ; 77.9-86.1)$ & $195(82.6 ; 77.2-87.2)$ & \\
\hline
\end{tabular}

95\% C I = 95\% confidence interval for the proportion;

Table 3: Community and patient opinions on access to TB diagnosis for presumptive TB patients 


\begin{tabular}{|c|c|c|}
\hline Variables & $\begin{array}{l}\text { Community }(\mathrm{n}=597) \\
\mathrm{n}(\%)\end{array}$ & $\begin{array}{l}\text { Patients }(\mathrm{n}=51) \\
\mathrm{n}(\%)\end{array}$ \\
\hline \multicolumn{3}{|c|}{ Duration to get to a health facility that diagnoses and treats TB? } \\
\hline$<1$ hour & $8(1.3)$ & 0 \\
\hline$\geq 1$ hour & $589(98.7)$ & $51(100)$ \\
\hline \multicolumn{3}{|c|}{ Availability of other health facility closer to the respondent's village } \\
\hline Yes & $344(57.6)$ & $13(26.0)$ \\
\hline No & $253(42.4)$ & $37(74.0)$ \\
\hline \multicolumn{3}{|l|}{ Is the TB care health facility easy to get to? } \\
\hline Yes & $429(71.9)$ & $44(86.3)$ \\
\hline No & $168(28.1)$ & $7(13.7)$ \\
\hline \multicolumn{3}{|c|}{ Do people have to pay for transportation to get to the health facility? } \\
\hline Yes & $356(59.6)$ & $37(72.5)$ \\
\hline No & $241(40.4)$ & $14(27.5)$ \\
\hline \multicolumn{3}{|c|}{ Do they have to pay to see a healthcare provider? } \\
\hline Yes & $163(27.3)$ & $11(21.6)$ \\
\hline No & $434(72.7)$ & $40(78.4)$ \\
\hline \multicolumn{3}{|c|}{ Do they have to pay to see have the laboratory test done? } \\
\hline Yes & $273(45.7)$ & $23(45.1)$ \\
\hline No & $324(54.3)$ & $28(54.9)$ \\
\hline \multicolumn{3}{|c|}{ Does the health facility have convenient hour's services? } \\
\hline Yes & $311(52.1)$ & $33(64.7)$ \\
\hline No & $286(47.9)$ & $18(35.3)$ \\
\hline \multicolumn{3}{|c|}{ Site of first visit in the community to seek care for cough } \\
\hline Self-treatment & $181(30.3)$ & \\
\hline Traditional healer & $86(14.4)$ & \\
\hline Public clinic/hospital & $120(20.1)$ & \\
\hline Private clinic / hospital & $18(3.0)$ & \\
\hline Patent medicine vendors/'chemist' & $191(31.9)$ & \\
\hline Prayer houses for faith healing & $7(1.2)$ & \\
\hline Others & $4(0.7)$ & \\
\hline \multicolumn{3}{|c|}{ Do you take self-prescribed medication before you visit the clinic when ill? } \\
\hline Yes & $405(67.8)$ & \\
\hline No & $192(32.2)$ & \\
\hline \multicolumn{3}{|l|}{ Where do people prefer to be treated for TB? } \\
\hline Government health facility & $472(79.1)$ & \\
\hline Private hospital & $94(15.7)$ & \\
\hline Others & $31(5.2)$ & \\
\hline \multicolumn{3}{|c|}{ Received information about TB in the last six months } \\
\hline Yes & $161(27.0)$ & $35(68.6)$ \\
\hline No & $436(73.0)$ & $16(31.4)$ \\
\hline \multicolumn{3}{|l|}{ Source of information about TB $(\mathrm{N}=161)$} \\
\hline Healthcare provider & $75(46.6)$ & $23(45.1)$ \\
\hline Mass media & $43(26.7)$ & $1(2.0)$ \\
\hline Family/friends & $20(12.4)$ & $14(27.5)$ \\
\hline Church & $12(7.5)$ & $1(2.0)$ \\
\hline Patent medicine vendor / 'chemist' & $11(6.8)$ & $12(23.5)$ \\
\hline
\end{tabular}

Table 4: Predictors of good community knowledge of and attitude to TB in riverine areas of the Niger Delta 


\begin{tabular}{|c|c|c|c|}
\hline Variables & $\begin{array}{l}\text { Crude OR } \\
95 \% \text { CI }\end{array}$ & $\begin{array}{l}\text { Adjusted OR } \\
95 \% \text { CI }\end{array}$ & $\begin{array}{c}\text { Adjusted } \\
\text { p-value }\end{array}$ \\
\hline \multicolumn{4}{|l|}{ Factors associated with good knowledge } \\
\hline Older age ( $>40$ years) & $1.5(1.1-2.2)$ & $1.5(1.1-2.3)$ & 0.042 \\
\hline Male sex & $1.0(0.8-1.5)$ & $1.0(0.7-1.5)$ & 0.875 \\
\hline No formal education & $1.3(0.7-2.5)$ & $1.2(0.6-2.5)$ & 0.583 \\
\hline Rural residence & $1.8(1.2-2.8)$ & $2.4(1.7-4.0)$ & 0.001 \\
\hline Ijaw ethnic group & $2.3(1.1-5.0)$ & $2.2(1.0-4.8)$ & 0.056 \\
\hline Itsekiri ethnic group & $2.0(0.7-5.2)$ & $3.0(1.1-8.8)$ & 0.043 \\
\hline Other ethnic group & $1.3(0.5-3.2)$ & $1.4(0.5-3.4)$ & 0.515 \\
\hline Having irregular income & $1.2(0.8-1.7)$ & $1.2(0.8-1.8)$ & 0.312 \\
\hline Having a regular income & $2.2(1.4-3.5)$ & $2.4(1.4-3.9)$ & $<0.001$ \\
\hline Being divorced/separated from partner & $1.3(0.6-3.4)$ & $0.9(0.3-2.3)$ & 0.799 \\
\hline Being a widow & $1.2(0.4-3.3)$ & $0.8(0.3-2.5)$ & 0.683 \\
\hline Being married & $1.1(0.8-1.7)$ & $0.8(0.5-1.3)$ & 0.349 \\
\hline \multicolumn{4}{|l|}{ Factors associated with Appropriate attitude } \\
\hline Older age ( $>40$ years) & $1.0(0.6-1.5)$ & $0.9(0.5-1.5)$ & 0.707 \\
\hline Male sex & $1.0(0.7-1.5)$ & $0.9(0.6-1.5)$ & 0.757 \\
\hline Having formal education & $4.8(1.1-20.2)$ & $5.8(1.3-25.6)$ & 0.020 \\
\hline Rural residence & $0.5(0.3-0.9)$ & $1.1(0.5-2.2)$ & 0.846 \\
\hline Ijaw ethnic group & $1.1(0.4-3.2)$ & $0.9(0.3-2.8)$ & 0.873 \\
\hline Itsekiri ethnic group & $6.0(1.8-20.2)$ & $6.1(1.6-23.6)$ & 0.009 \\
\hline Other ethnic groups & $0.6(0.2-2.4)$ & $0.6(0.1-2.3)$ & 0.421 \\
\hline Having irregular income & $1.5(0.9-2.5)$ & $1.3(0.7-2.1)$ & 0.405 \\
\hline Having a regular income & $1.4(0.8-2.5)$ & $1.1(0.6-1.9)$ & 0.905 \\
\hline Being divorced/separated from partner & $0.8(0.2-2.4)$ & $1.0(0.3-3.3)$ & 0.972 \\
\hline Being a widow & $1.3(0.4-4.1)$ & $0.8(0.2-3.5)$ & 0.805 \\
\hline Being married & $0.9(0.6-1.5)$ & $1.1(0.6-1.9)$ & 0.786 \\
\hline Having good knowledge & $2.3(1.4-3.7)$ & $2.5(1.5-4.4)$ & $<0.001$ \\
\hline
\end{tabular}

$\mathrm{OR}=$ odds ratio; $\mathrm{TB}-=$ tuberculosis

Table 5: Patients' knowledge of TB in the riverine areas of the Niger-Delta $(\mathrm{N}=51)$

\begin{tabular}{ll}
\hline Variable & Total correct \\
& $\mathrm{n}(\% ; 95 \%$ C.I. $)$ \\
\hline Total & 51 \\
Knowledge & $41(80.4 ; 66.9-90.2)$ \\
Have heard of or known about TB & $46(90.2 ; 78.6-96.7)$ \\
Knew that TB is a serious disease & $38(74.5 ; 60.4-85.7)$ \\
Knew that TB is caused by an infectious agent / germ & $47(92.1 ; 81.1-97.8)$ \\
Identified at least one common symptom of TB & $39(76.5 ; 62.5-87.2)$ \\
Knew that TB may be transmitted through inhalation of air droplet from affected persons & $51(100 ; 56.1-82.5)$ \\
Knew at least one means of diagnosing TB & $49(96.1 ; 86.5-99.5)$ \\
Knew that TB can be cured & $36(70.6 ; 56.2-82.5)$
\end{tabular}

95\% C I = 95\% confidence interval for the proportion; TB = tuberculosis

Table 6: TB patients' perceptions of and experiences with tuberculosis in the Niger-Delta $(\mathrm{N}=51)$ 
Do you think TB patients should be supported with:

Free TB medicines

$27(52.9)$

Food support

$24(47.1)$

Transportation to access health centres

$0(0.0)$

Should people with TB disclose their illness to other people?

Yes

43 (84.3)

No

8 (15.7)

Which of these individual is more likely to get TB?

Men

17 (33.3)

Women

29 (56.9)

I don't know

$5(9.8)$

What did you feel when you found out you had TB?

Scared

29 (56.9)

Depressed

8 (15.7)

Denial

$2(3.9)$

Calm

10 (19.6)

Other

Did you inform your family / friends that you have TB?

Yes

40 (78.7)

No

Have your relationship with your family changed since finding-out you have TB?

Yes

$23(45.1)$

No

Are people with TB discriminated against in your community?

Yes

$21(41.2)$

No

Are male or female TB patients more discriminated against in the community?

Male

$11(21.6)$

Female

7 (13.7)

I don't know

Have you been afraid you may lose your job if it is known that you have TB?

Yes

No

Have you been afraid you may lose your marriage if it is known that you have TB?

Do you think that TB will affect the ability of a woman to get pregnant and have healthy children?

Yes

No

Do women need permission from their husbands/relative to access health services? 
Table 7: Patients' health-seeking behaviour for TB and relationship with mean diagnosis delay $(\mathrm{n}=51)$

Page 23/25 


\begin{tabular}{l} 
Variables \\
\hline First symptoms that made you to seek treatment \\
Cough for more than two weeks \\
Sputum with blood \\
Fever \\
Chest pain
\end{tabular}

Did you take any treatment before being diagnosed for TB?

Yes

No

After you were given the treatment, what happened to the symptoms?
Improved

Worsened

Remained the same

I don't know $\mathrm{n}(\%)$

Diagnosis delay (wks)

35 (68.6) $\quad 24.4(24.6)$

7 (13.7) $7(4.9)$

8 (15.7) $\quad 13.8(8.8)$

$1(2.0) \quad 8.0(0)$

$50(98.0) \quad 20.3(21.8)$

$1(2.0) \quad 2.0(0.0)$

0.409

Why did you choose to come to this health facility to seek care?

Close to my home

Personal knowledge of the health provider

Other

Were you informed of the possibility of having TB when you came?

Yes

No

When (which visit/s) were you informed?

First visit

Other visit

$\begin{array}{ll}4(7.8) & 17.5(15.2) \\ 19(37.3) & 21.9(22.9) \\ 24(47.1) & 21.5(23.4) \\ 4(7.8) & 6.8(5.7)\end{array}$

8 (15.7) $15.5(24.6)$

$27(52.9) \quad 21.6(20.6)$

7 (13.7) $\quad 24.0(28.4)$

9 (17.6) $\quad 16.1(19.5)$

$29(56.9) \quad 16.8(15.9)$

0.246

$22(43.1) \quad 24.1(27.5)$

$24(47.1) \quad 21.3(24.6)$

$27(52.9) \quad 18.9(19.3)$

0.640

0.689

0.499

$\begin{array}{ll}22(43.1) & 21.2(22.6) \\ 13(25.5) & 15.5(21.6) \\ 12(23.5) & 27.2(22.8) \\ 4(7.9) & 6.3(4.0)\end{array}$

$\begin{array}{ll}22(43.1) & 23.0(25.8) \\ 16(31.4) & 22.1(22.0) \\ 9(17.6) & 10.4(9.6) \\ 4(7.8) & 16.8(13.7)\end{array}$

0.713

4 (7.8) $\quad 16.8(13.7)$

Different providers in the same facility

Different providers

I don't know

What type of health facility made the initial diagnosis?
48 (94.1) $20.4(22.3)$
2 (3.9) $\quad 19.5(6.4)$
$1(2.0) \quad 2.0(0)$
Government
Private
Other

What factors made you delay seeking care for symptoms that led to the diagnosis of TB?

Not aware of the severity of the symptoms

Expensive

Others

$\begin{array}{ll}35(68.6) & 22.4(24.5) \\ 9(17.6) & 18.3(13.7)\end{array}$

7 (13.8) $\quad 6.0(4.44)$

Received information about TB in the six months prior to diagnosis 
Source of information about TB

Healthcare provider

$23(45.1) \quad 22.3(20.9)$

$<0.001$

Mass media

$1(2.0)$

$6.0(0.0)$

Family/friends

$14(27.5) \quad 14.9(7.2)$

Patent medicine vendor / 'chemist'

$1(2.0)$

$15.0(0.0)$

Others

\section{Figures}

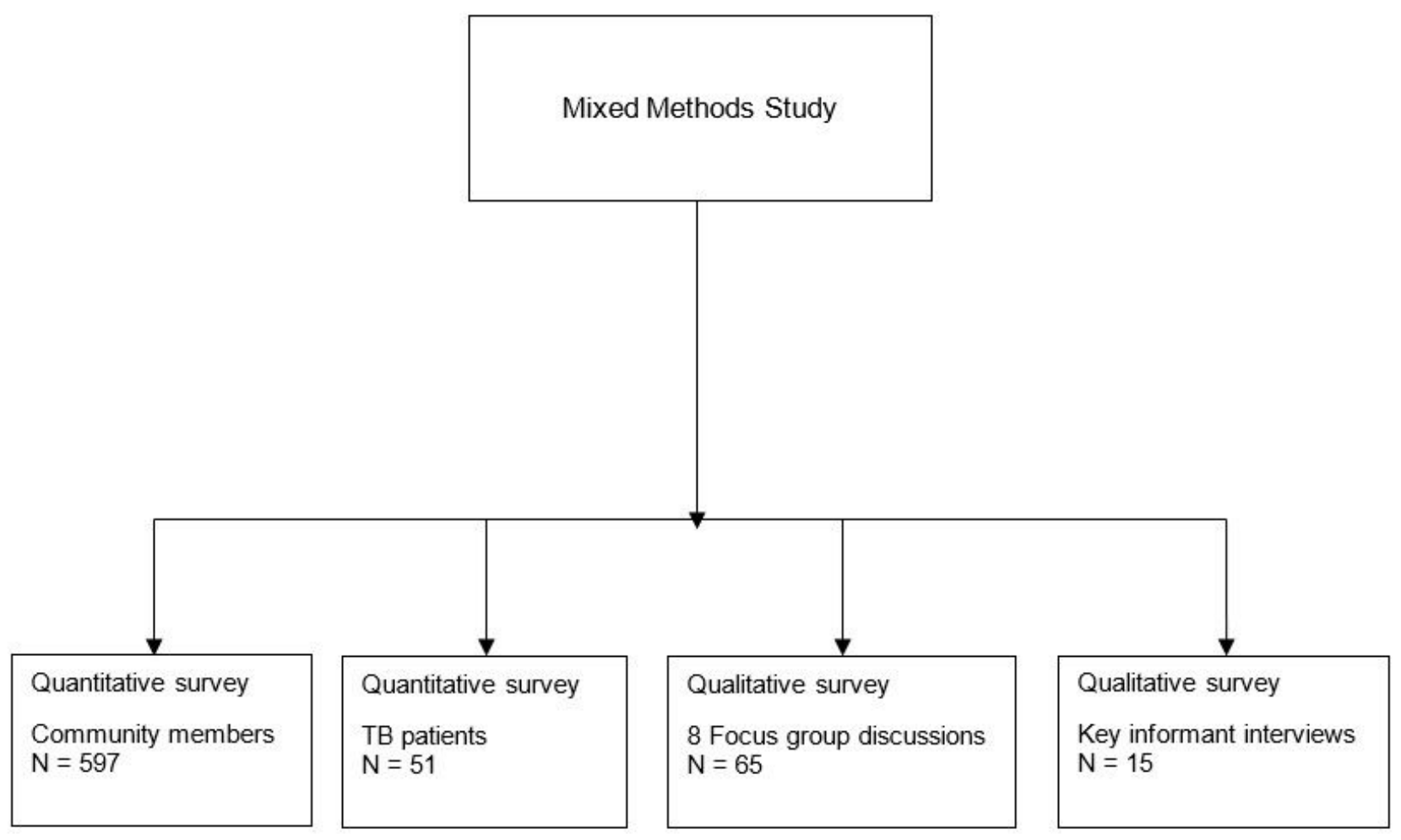

Figure 1

Sampling strategy for all patient groups in mixed-methods study

\section{Supplementary Files}

This is a list of supplementary files associated with this preprint. Click to download.

- SupTables.docx 